\title{
DESIGN AND BUILD: VIEWS FROM SOME MAJOR PUBLIC CLIENTS IN HONG KONG
}

Albert $P$ Chan and Danny C K Ho Department of Building and Real Estate, the Hong Kong Polytechnic University and C M Tam Department of Building and Construction, City University of Hong Kong

\section{Introduction}

A number of surveys on design and build (D\&B) procurement method were conducted recently (e.g. Akintoye, 1994; Akintoye and Fitzgerald, 1995; Bennett et al., 1996; Songer et al., 1996; Mo and Ng, 1997; Sanvido and Konchar, 1998). These studies usually adopted structured questionnaires as the data collection method. Respondents were asked to give some factual data on the D\&B projects they involved and express their level of agreement on some questions such as "Please indicate to what extent you have encountered the following problems in D\&B project". This type of response format can provide satisfactory answers for the "what" and "how" types of questions. By aggregating all the responses, this approach can assemble views from various parties and give a macro view on the overall picture.

Nevertheless, the survey method is less effective in answering the "why" type questions. It is difficult to gather some rich background information, which is important in the explanation of the subject matter through questionnaires. Instead of following the usual way of investigating the views of practitioners - using survey method, this study used interview method to explore two issues. First, this study investigated how some major public clients in Hong Kong viewed D\&B in general. Second, it examined their main reasons of adopting D\&B or adhering to traditional procurement method. Information about the situation under which clients made the procurement selection decision was also collected through interviews. The interview data were compared with secondary archival data, which helps researchers to better understand client's basis of using a particular procurement type. It is anticipated that this study can complement survey studies on D\&B procurement method.

This paper is divided into five sections. In the first section, past D\&B survey studies with focus on the reasons of using D\&B method are reviewed. Research methods are described in section two. The views of the Hong Kong Government and three institutional clients (statutory organizations with financial and administrative autonomy) in the public sector on D\&B method are presented in section three. More specifically, their rationales of using and not using D\&B method together with the situation they faced are described. Finally, discussion and conclusion are given.

\section{Review of D\&B survey studies}

According to the results of Design and Build Client Survey (Bennett et al., 1996), clients in the U.K. select D\&B method because of the following reasons (listed in descending order of importance):

1. Single point of responsibility

2. Guaranteed maximum price

3. Avoidance of design and construction risks

4. Avoidance of conflicts, disputes and claims

5. Better value for money

6. Faster building times

7. Reliability of completion on time

8. Lower costs

9. Flexibility of project team

10. Better understanding of commercial requirements

11. Guaranteed quality

12. Well though-out standard design

13. Innovative one-off designs

In general, these results are consistent with the findings of other procurement 
surveys. Songer et al. (1996) reported that the primary reason for both U.S. and U.K. clients to adopt D\&B method is to shorten the overall project completion time, while project cost certainty and reduction of the overall project cost are also important considerations. Some architects and builders in Hong Kong share a similar view that project time and project cost are the key factors for using D\&B method (Mo and $\mathrm{Ng}, 1997$ ). Various studies in the procurement selection literature also draw a similar conclusion. Industry experts in the U.K. and Australia consider D\&B as a viable method for clients who want responsibility for the project by one single organisation, transfer of the risks of cost and time slippage, firm price, strict completion date, early completion (Chan, 1995; Love et al., 1998; Skitmore and Marsden, 1988) and disputes and arbitration avoidance (Love et al., 1998).

D\&B method has been perceived by some practitioners as a method, which is most suitable for procuring buildings with simple and standardised design. A substantial amount of U.K. clients believe that D\&B method is appropriate for office building, warehouse, standard manufacturing facilities and residential building projects (Bennett et al., 1996). Architects think that it is most suitable for industrial buildings (factories) while contractors think that it is good for educational (schools), industrial (factories) and residential (housing) projects in Hong Kong (Mo and $\mathrm{Ng}$, 1997). However, some U.K. practitioners do not totally agree with the "garden shed" image associated with D\&B method (i.e. D\&B is only appropriate for procuring some very simple structures such as garden sheds). In Ndekugri and Turner's (1994) survey, a majority of contractors ( $98 \%$ of 74 respondents) strongly disagreed with the "garden shed" image. All clients also disagreed while $38 \%$ of architects disagreed and $25 \%$ agreed with this image. It seems that practitioners' general impression or expectation of the application of D\&B method does not always necessarily reflect its usage in reality. In fact, D\&B method has been applied to various types of complex projects such as health/hospital, civil engineering and refurbishment (Akintoye, 1994; Akintoye and Fitzgerald, 1995).

Nevertheless, it appears that the majority of practitioners tend to hold the view that it is difficult to apply D\&B method successfully to building projects with requirements of a high standard of design quality and workmanship. This preconception of the application of D\&B method influences procurement selection process substantially. It is, therefore, not surprising to find that neither guaranteed quality nor innovative design is considered by the U.K. clients as an important procurement selection criterion in Bennett's et al. (1996) survey. Some of the clients even believe that poor quality is the major drawback of D\&B method (Bennett et al., 1996). Design quality was also ranked as a minor selection criterion for D\&B method by architects and builders in Hong Kong (Mo and Ng, 1997).

\section{Research methods}

Clients who were familiar with D\&B procurement method or had participated in D\&B projects from the public sector were invited to give their views on and reasons of using D\&B method through face-to-face interviews. Active clients with recent completed building projects were the key focus of this study. Ten senior staff including assistant director, deputy senior manager, senior architect and senior quantity surveyor from four client organizations were interviewed. Most of them had direct involvement in D\&B projects. These senior staff were selected because they were the key 'actors' in procurement method selection process.

These four client organizations were regarded as the major ones because either they had a considerable number of building projects initiated every year or the projects they initiated were large in scale. Another reason to select these clients was that their requirements and project attributes were diverse; a mix of reasons accounting for the use of a particular procurement method might be revealed. 
Interviewees were asked some openended questions to explore why a particular procurement method was adopted. Survey research normally asks respondents to rate or rank a list of selection criteria for data collection. This was avoided in the current study because such a list may limit or direct interviewees to response in a certain format predetermined by researchers. Face-toface interviews were conducted in clients' offices and lasted about 1 to 1.5 hours. The length of the interviews varied according to the time afforded by the interviewees and the detail of their answers. The main focus of interview questions was on the reasons of using or not using D\&B procurement method. Background information about client's organisation and relevant projects was also collected to strengthen researchers' understanding of client's decision on procurement method. In addition, the interview data were documented and compared with secondary, archival data pertaining to the rationale of adopting $D \& B$ procurement method whenever possible. Collecting and comparing data from multiple sources (interviews and archives in this study) helps researchers to build credibility of the findings.

\section{Findings}

\section{The Hong Kong Government's views on D\&B method}

Since the first edition of the Design and Build Contracts issued by the Hong Kong Government in the early 1990s, a growing number of $D \& B$ projects in the public sector have been undertaken. In particular, since 1986 Architectural Services Department of the Hong Kong Government has taken the lead to promote the usage of D\&B method (Kwong, 1996) on various types of buildings including godown, depot, flying service headquarters, quarters, offices, schools and slaughterhouse. The results of the completed projects are well received and more public D\&B projects will be proposed.
According to a technical note issued by Works Branch of the Hong Kong Government (Works Branch, 1992), D\&B method is useful when:

- Fast-tracking is important

- Contractor's special skills and techniques are to be utilized

- Innovative design is anticipated

- Design economy is required

\section{Fast-tracking}

Among the above four factors, almost all clients' project team members highlighted short project delivery time as a key consideration for using D\&B method. For example, there was an urgent demand for some quarters a few years ago and D\&B method was used for its fast-tracking capability. One interviewee from a client's project team indicated that the total project lead-time could be shortened by some $30 \%$ for typical quarters. Significant time saving did not come from shortened construction period but from the subletting of design development to D\&B contractor and the overlapping of design and construction.

Contractor's special skills and
techniques

Apart from time consideration, some client's project team members pointed out that the utilization of contractor's special design and construction skills and techniques was an important factor for using D\&B method. An example is the project of system design and construction of standard schools. This project called for a system design and construction method, which was particularly cost-effective in some building structures with repetitive parts such as schools. In this project, client wanted to examine whether this special method would offer advantages over the traditional construction method.

Instead of following the traditional way of building schools such as using timber formwork, bamboo scaffolding, and wet trade, the contractor adopted a system method of design to construct the schools in an environmental-friendly manner. 
Semi-precast elements were used extensively to achieve a consistent level of quality and save construction time. Since the surface finishing achieved by steel formwork had met the required standard, the use of wet trade was reduced. This, in turn, could lessen client's burden of future maintenance. Building wastes could also be reduced substantially with the use of steel formwork because the steel molds have a much longer working life than timber formwork.

On the surface, it appears that contractor's involvement in developing a design for a D\&B project is little if client has adopted a standard design, which is the case for most schools in Hong Kong. In this school project, however, the client provided only architectural design and layout of building services and left the structural design to the D\&B contractor. This variant of $D \& B$ methods does not resemble traditional $D \& B$ where client only provides requirements and specifications to a contractor who develops the complete design and constructs the building. It is different from novation because there is no transfer of client's consultants to contractor's design team (Chan, 1994). Nevertheless, it shares some of the characteristics of enhanced D\&B method where contractor develops detail design based on the initial design provided by the client and constructs the building (Mo and $\mathrm{Ng}, 1997)$. This special type of $\mathrm{D \& B}$ methods enables the client to both maintain a tight control on the architectural and building services design and capture contractor's unique building capability through contractor's involvement in the structural design.

\section{Innovative design}

Anticipating innovative designs proposed by contractors was never mentioned by the client's project team members as an important procurement selection criterion. For example, one interviewee indicated that the architectural design for government's office building in D\&B project would not be very innovative because client required a general type of office and emphasized more on the functionality of the building. This is different from other large corporations such as The Hongkong and Shanghai Bank, which stresses the corporate image reflected by the design of its headquarter. Client's budget is another important consideration for the procurement of a building with an innovative design. Clients in private sector may be willing to pay more for superior design than government who has to account to the public for all the money spent. Nevertheless, one interviewee pointed out that contractors would explore different new architectural designs and try something innovative only if cost saving could be brought. It would be a bonus for the client if the design developed by the successful tenderer were innovative.

\section{Design economy}

Regarding design economy, client's project team pointed out that competition would drive D\&B tenderers to develop design, which was economical both in concept and detail. Also, client would have more design schemes for selection, as the proposals submitted by various tenderers are different. If client follows the traditional procurement method, only a very limited design options would be developed by the project architect for selection. In general, more design alternatives to be proposed imply more consultant fee the client has to pay. However, D\&B method enables the development of a number of different design options at the expense of the tenderers. The results of our study indicate that interviewees did not feel design economy as the most important procurement selection criterion. Nevertheless, client's project teams suggested that if client wanted more options of economical design, D\&B would be a good method to achieve it.

Sometimes D\&B method would not be used even a project displays appropriate characteristics. One interviewee indicated that it might not be appropriate to procure some buildings such as court and police station using D\&B method for their special security requirements. The client requires full control in the design. In fact, this type 
of buildings has never been procured by D\&B method in Hong Kong.

It is also interesting to find that in a government's project, client changed the procurement method from traditional to $D \& B$ at a stage where some design outlines had been developed. One of the main reasons for such a change was that there was insufficient in-house staff to develop a complete design. Since the client had developed the initial design, enhanced D\&B method was adopted and contractor only needed to develop detail design following what had been completed and required by the client.

\section{Three views of institutional clients in the public sector on D\&B method}

\section{Switching from traditional to $D \& B$ procurement method}

Our findings indicate that one institutional client in the public sector has embarked on a new path to procure buildings partly because of the advantages the new method offers and partly because of political consideration. The variety of the buildings this client procures is limited but most of them require heavy building services. Since the number of end-users involved in a typical project of this client is large and their requirements are diverse, pre-construction planning process could be lengthy. It is not unusual to take a decade to plan, design and construct a building required by this client using traditional procurement method.

For the government funded building projects, this client has little involvement in the procurement selection process. There is a government department, acting as a representative of this client, decides the procurement method and manages the project. Traditional method has been used to procure buildings by this department for a long time. In fact, the client has little influence on the design and project management under such an arrangement.

Some years ago, this client was requested by the Government to procure a building within a time frame, which could never be completed if traditional method had to be used. The requirement of short project delivery time provided a strong justification for this client to explore alternative procurement methods other than the traditional one. Cost certainty was also an important selection criterion to be addressed for public project. Having considered different procurement options, this client proposed enhanced D\&B method as a viable means to finish the project within time and budget constraints. Since the planning of end-users' relationships and requirements involved lots of efforts and expertise, this client was reluctant to hand over everything to a D\&B contractor at the very early stage.

Therefore, traditional D\&B method was not considered. After the suggestion of enhanced D\&B procurement method had been approved by a government steering committee, this client and his consultants started to plan, identify end-users' requirements, establish client's brief, develop the initial design, prepare tender document and undertake other project management activities.

Adopting a new procurement approach implies a change to the status quo. This client was able to break the old way of doing things by using D\&B procurement method. He had assumed a dominant role in this D\&B project - acted as an agent of the government to manage the project, while that government department, which used to be the leader, only provided a supportive function this time. This client's influence was extended even further with the enhanced D\&B method. He exerted a tight control over the design by developing not only an explicit functional brief but also an initial design to ensure all end-user's requirements were addressed. Completing this project with the required standard of quality on time and within budget was by no means an easy task for this client. It is because he did not have any experience in using D\&B method before. Also, the building to be procured was complex. Nevertheless, this client determined to take the challenge and perhaps more important is that he could gain more control in both design and project 
management when D\&B method was used.

The performance of this D\&B project was well received and all objectives were met. Based on these successful results, this client had a stronger stand on the initiation of his second D\&B project although the required project completion time was not as tight as the first one.

\section{Switching from $D \& B$ to traditional procurement method}

From our study, it is interesting to find that an institutional client in the public sector has used two different methods to procure the same type of building at different times. D\&B and traditional procurement methods were used for the first and second logistic center projects respectively. The second one with a larger scale will replace the old one once completed. Although this client had procured some buildings before, he was not as familiar to the design and construction issues as other experienced clients were. The majority of the staff in this organization had extensive business experience and strong administrative skill; however, they did not share the same language with architects and builders.

This client suggested that there was a lack of in-house building professionals to oversee the whole project at that time, so D\&B method was adopted. Using this method could free client from spending lots of manpower on the project because the responsibility for delivering the whole product was shifted to the $D \& B$ contractor. After the decision of using D\&B method had been made, a business executive who had little architectural and building knowledge was appointed to take charge of this project. The client developed a functional brief of this industrial building and then a contractor was appointed for design and construction. On completion of the project, the client was satisfied with the building in terms of the achievement of the basic functional requirements. However, this client was not happy with the standard of quality delivered; he found what he got was so minimal in terms of quality. For example, water pipes in toilets were not concealed. Such "surprises" could be attributed to the comprehensiveness to which the client's brief was specified. This client might take some seemingly simple requirements for granted and expect the contractor would deliver a building with the "normal" standard. Perhaps the client did not have any experience in handling a D\&B project and did not recognize the fact that no matter how basic the requirements are, if they have not been stated in the client's brief or do not provide sufficient details, the contractor can build exactly what the client wants only by chance. Certainly, this client has learned much from this D\&B project.

Some time later this client was commissioned to design, construct and manage a large scale and complex building project. Professionals from various disciplines were recruited to oversee this project. Much emphasis had been put on the requirement of superior design quality because this building was purposed to become a new landmark of Hong Kong. Although this project had to be completed in a very short time, traditional procurement method was used. Nevertheless, fast tracking project management principles were used to speed up the project delivery process.

During that time, a new logistic center with size doubles the previous one was planned to be built to cope with the growing demand. Instead of following D\&B approach, traditional method was used to procure this building. The staff responsible for this project was no longer business executives but in-house architects and professional builders. The client pointed out that the key reasons for the choice of traditional procurement method was that there was sufficient professional staff to manage the project and client had a strong control on the design. 


\section{Sticking to traditional procurement method}

The results of our study indicate that not all public clients think that D\&B procurement method is suitable for their projects although most of the D\&B projects are public projects in Hong Kong. Those who have never used D\&B method think that it does not have any advantage over traditional procurement method, which is the practice they stick to. It is interesting to know why different views on the same procurement method are held by public clients, which can possibly give some insights on the applicability of D\&B method in the public sector.

It appears that the characteristics of these public clients' projects could account for why they are in favor of traditional procurement method. The projects of these clients exhibit the following characteristics:

- Only a single and simple type of building is to be procured.

- Virtually, the designs of all building projects are standardized and there are limited varieties of them.

- Buildings are procured according to a well-planned schedule.

- End-users' requirements are known in advance and less likely to be changed once established.

- Conventional methods are used to construct the buildings in most cases.

On the surface, applying D\&B method to simple building projects with firm endusers' requirements should not cast any serious problems. It is because the demand for sophisticated design management capability from the contractor is little and the disruption to contractor's design and construction process is minimal. Nevertheless, these public clients think that traditional method is the most appropriate way to procure their buildings for the following reasons.

First, the benefit of D\&B method is difficult to be reaped. Given that the complexity of these projects is not that high, most contractors can construct the buildings without much difficulty using conventional method. The demand of utilizing a particular contractor's special, unique expertise in design development and construction, which is an advantage of D\&B method, is therefore small.

Second, adoption of standardized design helps to improve contractors' productivity, which in turn reduces project delivery time. The involvement of contractor in developing design is not required in these projects because standardized designs are used. Procuring a large number of buildings using limited, standardized designs can motivate contractors to invest in the improvement of their construction methods to reduce cost and project delivery time, which can enhance their chance of winning contracts. Maybe the initial investment is substantial; however, the financial return will be realized in the repeated contracts. Although contractors have little chance to influence the design, their productivity could be raised in the long run. Obviously, it is the contractor's continuous improvement in their efficiency and not any procurement method that can bring significant time savings in this case.

Third, it is the Government's long-term plan and policy targets that directly determine the supply of the buildings (Walker and Flanagan, 1991), although the supply has never been able to cope with the growing demand. Most of the buildings are procured at a planned pace which is less likely to be altered dramatically in a short term even in face of higher demand. Since alternative way of increasing supply can be obtained through the use of private sector resources, using D\&B method to boost client's speed of procuring buildings is not normally considered.

$D \& B$ method may be attractive to these clients in the future if different designs are promoted, short project completion time is required, and the cost of using $D \& B$ method is comparable with that of traditional method. 


\section{Discussion}

Based on the findings of this study, the rationales of adopting $\mathrm{D \& B}$ and sticking to traditional procurement method are summarized in Fig. 1. In general, clients in the public sector of Hong Kong construction industry share a similar set of reasons of adopting $D \& B$ procurement method when compared with their counterparts in the U.S., U.K. (Bennett at al., 1996; Songer et al., 1996) and Australia (Chan, 1995). Short project completion time and to a lesser extent utilisation of contractor's expertise have been frequently mentioned by clients as important considerations in using D\&B method. These considerations also match the secondary, archival data of Works Branch (1992). An institutional client also considered Price certainty as a major factor in proposing a D\&B project. It is not surprising to find that clients in the public sector assigned these considerations a high priority because they have to account to the public for every dollar they spent. In fact, public accountability was also reported as an important selection criterion by public clients in Chan's et al. (1999) and Ng and Mo's (1997) studies. The pressure put on these clients is even higher in the time of economic downturn where public institutions' budget and spending are under close surveillance by the public. It is expected more public works will be procured by D\&B method in the future because clients can have a better control on project completion time and budget.

\section{(See Figure 1 over)}

In addition, none of the clients in the public sector mentioned that a superior standard of quality in terms of design and construction was the key reason of using D\&B. These results are consistent with the findings of past surveys (e.g. Bennett at al., 1996). This may be probably due to client's perception of contractor's main concern - cost. Since D\&B contractor is responsible for not only construction but also design, chances provided for the contractor to exploit loopholes or grey areas in the contract may be more.
Contractors could sacrifice both design and building quality if they want. Their incentive to undercut quality could be higher in the case where keen competition drives the tender price to an unreasonable low level.

Of particular interest in our findings is that apart from functional considerations (e.g. project completion time, cost certainty, etc.), factors including internal resources and political force were also important in shaping clients' decision in the adoption of D\&B method in the public sector. Since the resource spent on the development of a complete design is substantial, D\&B method could be an effective means to shift workload from client's project team to contractor in the situation where client's manpower is insufficient. In one of cases mentioned before, client has taken the advantage of using D\&B method to increase his control over the design and project management. Nevertheless, this procurement method can also fulfil his requirements on short project completion time and cost certainty.

Moreover, client's past experience with $D \& B$ project is influential in deciding the adoption of D\&B method for future projects. If clients have bad experience with D\&B project, they may become more cautious of using D\&B method because poor performance could recur. On the contrary, if clients have completed D\&B project successfully, they may have more confidence in using D\&B method and in the performance of subsequent D\&B projects.

\section{Conclusion}

Although the Hong Kong Government has been promoting D\&B method since the late 1980s and early 1990s, the results of this study indicate that the views of clients in the public sector on D\&B method are diverse. Some institutional clients in the public sector have used D\&B method just once and then reverted to the traditional one while some keep seeking every possible chance to depart from the traditional way and continue to use D\&B method. Some clients in the public sector 
have never used it and do not think it is attractive. All these interesting contrasts reveal that there is not a single reason that explain why some clients use D\&B method and some do not to use it. Their decision making was based on different grounds. Simply saying that certain procurement methods are more appropriate for a particular type of clients will oversimplify the complex reality.

Fig. 1 Summary of client's considerations in making procurement selection decision

\begin{tabular}{|c|c|c|}
\hline \multicolumn{3}{|c|}{ To } \\
\hline 7 & D\&B method & Traditional method \\
\hline 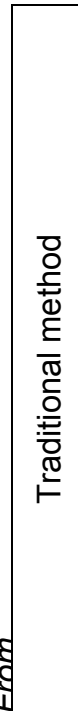 & $\begin{array}{l}\text { Functional consideration: } \\
\text { - Fast-tracking } \\
\text { - } \quad \text { Firm price } \\
\text { - Make use of contractor's special } \\
\text { - } \quad \text { Skills and techniques } \\
\text { Political force: } \\
\text { - More control on the design and } \\
\quad \text { project management } \\
\\
\text { Resource consideration: } \\
\text { - Inadequate in-house staff to } \\
\text { manage the project }\end{array}$ & $\begin{array}{l}\text { Functional consideration: } \\
\text { - } \quad \text { Standard design } \\
\text { - } \quad \text { usenventional building methods are } \\
\text { - Security } \\
\text { Supply consideration: } \\
\text { - Buildings are procured following a well } \\
\text { planned schedule } \\
\text { End-users' requirements are known } \\
\text { and less likely to be changed once } \\
\text { established } \\
\text { Resource consideration: } \\
\text { - Adequate in-house staff to manage the } \\
\text { project }\end{array}$ \\
\hline 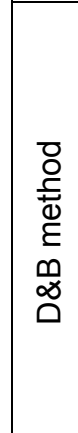 & $\begin{array}{l}\text { Functional consideration: } \\
\text { - Fast-tracking } \\
\text { - } \quad \text { Firm price } \\
\text { Past experience: } \\
\text { - Satisfactory project results delivered } \\
\text { by D\&B method } \\
\text { Political force: } \\
\text { - Control on the design and project } \\
\quad \text { management can be maintained }\end{array}$ & $\begin{array}{l}\text { Functional consideration: } \\
\text { - More control on the design } \\
\text { Past experience: } \\
\text { - Unsatisfactory project results delivered } \\
\text { by D\&B method } \\
\text { Resource consideration: } \\
\text { - Adequate in-house staff to manage the } \\
\quad \text { project }\end{array}$ \\
\hline
\end{tabular}




\section{References}

Akintoye, A. (1994) Design and build: a survey of construction contractors' views, Construction Management and

Economics, 12, 155-163.

Akintoye, A. and Fitzgerald, E. (1995) Design and build: a survey of architects' views, Engineering, Construction and Architectural Management, 2(1), 27-44.

Bennett, J., Pothecary, E. and Robinson, G. (1996) Designing and building a worldclass industry. Centre for Strategic Studies in Construction, University of Reading, Reading, U.K.

Chan, A. P. C. (1994) Evaluation of novation contract, National construction and Management Conference, 17-18 February, 1994, Sydney, Australia, 383396.

Chan, A. P. C. (1995) Towards an expert system on project procurement, Journal of Construction Procurement, 1(2), 111-123.

Chan, A. P. C., Yu, A. T. W. and Tam, C. M. (1999) Enhanced design build - An innovative system to procure a hospital project, CIB W92 and CIB TG23 Profitable Partnering in Construction Procurement, Procurement Systems and Culture in Construction Joint Symposium, 25-28 January, 1998, Chiang Mai, 405-415.

Kwong, H. S. (1996) The strategic role of design and build in the procurement process, Keynote Address at Design and Build Symposium, 30 May, 1996, Hong Kong, 1-4.

Love, P. E. D., Skitmore, M. and Earl, G. (1998) Selecting a suitable procurement method for a building project, Construction Management and Economics, 16, 221233.

Mo, J. K. W. and Ng, L. Y. (1997) Design and build procurement method in Hong Kong - An overview, CIB W92 Procurement - A Key to Innovation, Procurement Systems Symposium, 20-23 May, 1997, Montreal, 453-462.
Ndekugri, I. and Turner, A. (1994) Building procurement by design and build approach, Journal of Construction Engineering and Management, 120(2), 243-256.

Ng, L. Y. and Mo, J. K. W. (1997) Hospital procurement by design and build: a case study in Hong Kong, CIB W92

Procurement - A Key to Innovation, Procurement Systems Symposium, 20-23 May, 1997, Montreal, 545-553.

Sanvido, V. E. and Konchar, M. D. (1998) Project delivery systems: CM at risk, design-build, design-bid-build. Research Report 133-11, Construction Industry Institute, University of Texas, Austin.

Skitmore, R. M. and Marsden, D. E. (1988) Which procurement system? Towards a universal procurement selection technique, Construction Management and Economics, 6, 71-89.

Songer, A. D., Molenaar, K. R. and Robinson, G. D. (1996) Selection factors and success criteria for design-build in the U.S. and U.K., Journal of Construction Procurement, 2(2), 69-82.

Walker, A. and Flanagan, R. (1991)

Property and construction in Asia Pacific: Hong Kong, Japan and Singapore. BSP Professional Book, Oxford.

Works Branch (1992) Practice Note on Design and Build Contracts, Works Branch Technical Circular No. 17/92A, Hong Kong Government. 